\title{
Pedagogias culturais das feminilidades: os endereçamentos masculinos do personagem Ken
}

Michely Souza* Universidade Estadual de Maringá

Samilo Takara** Universidade Estadual de Londrina

Teresa Teruya*** Universidade Estadual de Maringá

Resumo As masculinidades, bem como outras identidades de gênero, estão atreladas a sentidos que são consumíveis, transgressores e perpassam as relações dos sujeitos com os artefatos culturais e as possibilidades de ser, pensar e agir que derivam dessa relação. A partir disso, sugerimos uma interpretação dos endereçamentos de gênero oferecidos pelo personagem Ken nas narrativas da boneca Barbie. Para tal feito, nosso procedimental metodológico embasa-se nos estudos acerca dos modos de endereçamento que os sujeitos produtores oferecem para os/as receptores/as das peças, dos produtos e dos serviços da mídia. As masculinidades sugeridas por esta personagem não condizem com a ideia de masculinidade como virilidade, agressividade, rispidez ou força, mas denotam elementos como beleza, atenção e carisma, que fazem parte das representações hegemônicas de masculinidade.

PALAVRAS-ChAVE: Educação; Gênero; Mídia. 


\section{Pedagogies of cultural femininities: addresses the character male Ken}

Abstract Masculinities and other gender identities are linked to meanings that are consumable, transgressors and pervade the relations of subjects with cultural artifacts and the possibilities of being, thinking and acting that stem from this relationship. From this, we suggest an interpretation of gender assignments offered by the character Ken the narratives of the Barbie doll. Our aim is to present and discuss positions, practices and analyzes of suggested masculinities. Analyze masculinities offered in this representation as indicative of a male-female ratio. which shows a relationship between the suggested elements relate to the Barbie doll with these femininities indicative of masculinities. For this feat, our methodological approach was grounded in studies about addressing modes that the subject producers offer for / the receivers / the parts, products and media services. That masculinities suggested by this character do not match the idea of masculinity and virility aggressiveness, rudeness or strength, but denotes elements such as beauty care and charisma, which are part of the hegemonic representations of masculinity.

KEYWORDS: Education; Gender; Media.

\section{Introdução}

As alterações sociais, culturais, políticas e econômicas que envolvem os conceitos de tempo e espaço modificaram as formas como compreendemos a constituição das identidades. Com base nos Estudos Culturais em Educação, problematizamos as possibilidades de construir sentidos e significados sobre representações midiáticas, aspectos culturais e relações de gênero e sexualidade. Nossas pesquisas buscam as representações culturais acerca das identidades femininas e homossexuais nas produções midiáticas, tais como filmes, músicas, textos jornalísticos e materiais de entretenimento.

Com base em nossas indagações, nos debruçamos a discutir as masculinidades e sua construção de modos de ser e agir. Nosso intuito é problematizar a interferência das representações de gênero na constituição do binômio masculino-feminino produzido pela personagem feminina de expressão mundial - a boneca Barbie. A constituição de uma representação de masculinidade que faz referência ao par da boneca, que indica uma cultura heteronormativa, branca, monogâmica e de traços culturais eurocêntricos é o personagem Ken.

O boneco é o par ideal de Barbie. Loiro, com a pele bronzeada, olhos claros, de corpo delineado com músculos que caracterizam uma representação atlética. Entretanto, a masculinidade dessa personagem não segue um padrão hegemônico dos modos de ser masculino. Seria este personagem uma oportunidade de romper com os estereótipos de gênero ensinados a meninas e a meninos sobre o que é ser homem? Reportamo-nos às relações entre estudos de gênero, teorizações foucautianas e problematizações feministas para pensarmos outros modos de ler e interpretar os estereótipos de gênero ofertados para meninas e meninos. 
Nesta análise, problematizamos a constituição do período contemporâneo e como - neste momento histórico, cultural, social, político e econômico - inscrevem-se as representações de masculinidade e os estereótipos constituintes e constituídos na relação entre mídias, educação e gênero. Entendemos a mídia como um artefato cultural, ou seja, a recepção desses conteúdos é produzida nas e pelas culturas. Os modos de significar nossas concepções de masculinidades e feminilidades ficam atreladas as relações estabelecidas pelos grupos sociais nos quais produzimos nossas subjetividades e percepções.

Furlani (2009, p. 132) explica que as mídias incitam significações das relações sociais e das representações de gênero. Ao "[...] reforçar representações hegemônicas, ao sugerir certos tipos de conduta e comportamento (excluindo outros), parecem contribuir, ora para a manutenção, ora para a mudança da sociedade; ora para a regulação, ora para a subversão das regras sociais" (FURLANI, 2009, p. 132). Ressaltamos esse potencial de instabilidade dos significados e sentidos produzidos nas culturas para relembrar a noção de disputa que permeia os produtos e serviços midiáticos. A disputa por espaços de visibilidade e a lógica de mercado das produções midiáticas estão embutidas em lógicas de produção, seleção e distribuição dos conteúdos midiáticos. A diferença também está nessa disputa e precisa ser discutida e problematizada.

Ao vincularmos este conceito de artefato às práticas educacionais, percebemos coerência na conceituação fornecida por Furlani (2009) com a explicação de Michel Foucault (2009, p. 44), ao explicar que a educação "[...] é uma maneira política de manter ou modificar a apropriação dos discursos, com os saberes e os poderes que trazem consigo [...]". Desse modo, compreendemos que a constituição de saberes e poderes acerca das questões de gênero e sexualidade estão nas relações que constituímos e das quais produzimos como sujeitos do discurso.

Percorrendo as noções de razão e loucura, Foucault (2009) oferece argumentos que explicam o processo de exclusão que está na dinâmica do discurso. As representações de gênero estão dispostas em diversos espaços sociais e atribuem sentidos às feminilidades e às masculinidades culturalmente atribuídas no Ocidente contemporâneo, marcando, também, os processos de exclusão. Desse modo, podemos entender que o conceito de gênero é atribuído às feministas e às práticas de pesquisas em culturas e identidades para problematizar as significações atribuídas às feminilidades e as masculinidades.

Uma das precursoras dos estudos acerca do conceito de gênero, Joan Scott (1995, p. 72), explica que tal perspectiva tem o intuito de "[...] enfatizar o caráter fundamentalmente social das distinções baseadas no sexo". Essa definição parte dos estudos de feministas norte-americanas que rejeitam o entendimento do determinismo biológico. Desse modo, a autora reitera que essa é "[...] uma categoria social imposta sobre um corpo sexuado. Com a proliferação dos estudos sobre sexo e sexualidade, 'gênero' tornou-se uma palavra particularmente útil, pois oferece um meio de distinguir a prática sexual dos papéis sexuais atribuídos às mulheres e aos homens" (SCOTT, 1995, p. 75). 
Em nosso entendimento o conceito contribui para a inserção das discussões sobre sexualidade nas perspectivas de análise, mas não por base biológica. Essa constituição realiza-se nas sociedades e nas culturas entre as disputa pelas relações de poder e as práticas de resistência que determinam potencialidades para a constituição de olhares sobre os modos de ser mulher e de ser homem nas sociedades. Ao explicitarmos que "[...] o masculino e o feminino não são características inerentes, mas constructos subjetivos (ou ficcionais), a constituição dessas representações pode ser questionada, repensada e redimensionada em diferentes contextos" (SCOTT, 1995, p. 82). E, assim, percebemos que este conceito "[...] é uma marca de diferenciação social que incide em quaisquer relações - afetivas, de trabalho, na rua, no lazer - de forma que não pode ser ignorada" (BELELI, 2010, p. 46).

Visualizar essa delimitação por meio da perspectiva que abordamos neste trabalho, é um modo de indicar aos/às leitores/as os sentidos de apreciação das marcações culturais que são oferecidas às meninas e aos meninos. A mídia contribui com esse movimento e, por vezes, "[...] reforça concepções percebidas como tradicionais, mas essas convenções não são estáticas e fixas: é possível modificá-las de forma a produzir deslocamentos"(BELELI, 2010, p. 65). As práticas de desconstrução da ideia de essência permitem a leitura de diferentes representações de ser feminina ou masculino dentro dos padrões culturais, sociais, políticos e econômicos.

Inscritas nessas formas, analisar as noções de contemporâneo e culturas, o conceito de masculinidade é uma construção social, assim como a feminilidade. A pluralidade permite "[...] admitir não apenas que sociedades diferentes teriam diferentes concepções de homem e de mulher, como também que no interior tais concepções seriam diversificadas [...]” (LOURO, 1996, p. 10).

Essas performances movimentam os sentidos e as produções acerca de artefatos que registram os modos de relacionarmos com as masculinidades. Um exemplo dessa produção de sentidos é o termo barbie usado no gueto gay/homossexual para designar um padrão corporal que está relacionado ao bodybuilder, expresso por músculos definidos e um padrão corporal que mostra a ideia de atletismo e força.

\begin{abstract}
A imagem poética dos fortões, ou melhor das Barbies, se caracteriza nos rapazes que vivem nos clubes de fisioculturismo, de ginásticas e academias de musculação, especialmente, para trabalhar o corpo, solidificando-o com exercícios musculares, de respiração (aeróbicos e anaeróbicos), de pesos e medidas em séries de repetições [...]. O resultado disso tudo são marcas torneadas bem detalhadas que se espalham pelo corpo pontuando a rigidez plástica - moldando assim um varão (GARCIA, 2000, p. 49).
\end{abstract}

Essa marcação é pertinente para pensarmos na estética oferecida e produzida pelos brinquedos e pelas regras binárias de gênero. $\mathrm{O}$ boneco Ken apresenta essas marcações em produtos, desenhos e na metáfora corporal de plástico que o situa como parceiro da boneca Barbie, entretanto, o nome utilizado para o grupo é o da famosa personagem e não de Ken. Quais os sentidos que este marcador cultural expõe para pensarmos a disposição deste personagem ou mesmo de sua masculinidade oferecida para pensarmos as pedagogias culturais que são forjadas na relação com o boneco? 
Mais especificamente, indagamos acerca das possibilidades que o personagem Ken sugere representações de masculinidade que significam elementos das culturas, assim como sua consorte é apresentada como ideal de feminilidade a meninas e mulheres.

Não fixado ao local de "homem" e de "bicha”, tal como sugere Green (2000), a marcação de gênero que separa em polos a masculinidade e a feminilidade no padrão heterossexual, também sugere que aquele que não cumpra com o ideal de masculino como forte, viril, desejante e racional, não seja denominado, nesse sistema binário, como homem. É pertinente ressaltar que o personagem Ken, mesmo sendo o parceiro do ideal de mulher proposto pela Barbie não é aclamado como o macho produzido em sentidos e significados como um sujeito viril, bruto e desejante. Galante, carinhoso e cuidadoso, o personagem rompe com elementos da performance dita masculina.

Whitaker (1988) explicita que os modos de ser menino são constituídos de forma diferente das práticas que constituem as feminilidades. Os meninos são abertos, soltos e produzidos em uma corporalidade que diferencia dos modos de ser mulher. "Hoje as meninas usam tênis e bermudas. Os cérebros femininos, no entanto, permanecem prisioneiros do autoritarismo que pesa sobre a necessidade de ser frívola, uma vez que a feminilidade está associada à frivolidade" (WHITAKER, 1988, p. 49). Enquanto as meninas e mulheres devem preocupar-se com cores, adereços, detalhes para a sua performance de gênero, nos limites de cores que podem ser usadas, as roupas masculinas são produzidas de forma mais confortável. Todo o armário feminino é produzido para mostrar que o conforto do masculino é negado ao feminino que, na lógica da visibilidade, precisa mostrar as curvas e os corpos.

Olhar para estas performances de gênero na masculinidade também sugere que o Ken, com seus modelos e roupas que são estruturadas, delineadas e valorizam o padrão corporal produzido em um ideal atlético e esportivo, não buscam conforto. Estes detalhes marcam os sentidos de corporalidade que não seguem pressupostos de masculinidade, entretanto, sugere movimentos e marcam que "[...] vivemos numa cultura das aparências [...]"(TREVISAN, 2000, p. 21), e personagens, bonecos, como artefatos culturais, indicam os sentidos construídos na cultura

\section{Masculinidades possíveis: os endereçamentos de Ken}

Como objeto de análise, utilizamos um vídeo disponível no canal YouTube que possui como tema a importância de Ken no cotidiano da boneca Barbie. O vídeo consiste em um trecho da série que Barbie possui online, denominada Life in the Dreamhouse, disponível também no site oficial da boneca ${ }^{1}$, a série foi lançada em 2012 e também foi exibida nos programas, Bom dia e Companhia e Sábado animado, ambos da emissora televisiva SBT.

O episódio conta com uma música ${ }^{2}$ cantada pela $\mathrm{Barbie}^{3}$, cujo tema é o namorado Ken. As cenas apresentadas durante o vídeo mostram o personagem desenvolvendo tarefas que agradam Barbie. Ele lhe oferece presentes e flores, deixa Barbie tratar de seus cabelos, constrói uma loja de roupas para Barbie, vai às compras com ela e segura suas sacolas, mima a boneca quando ela está doente, fazem encontros românticos etc. Trechos da música enfatizam a necessidade de todos/as terem um Ken como amigo, para conversar e para que sua vida torne-se agradável. 
Embora apresente características físicas valorizadas na contemporaneidade, como o corpo forte e definido, o boneco não faz parte dos brinquedos preferidos dos meninos. Ao mesmo tempo em que se impõe fisicamente como homem e namorado da Barbie, Ken mostra-se também delicado e empenhado em realizar todos os desejos da namorada e ajudá-la em todas as situações. As atitudes carinhosas de Ken revelam uma posição contrária do que as mídias representam sobre a masculinidade - agressividade, agilidade e rudez (LOURO, 2008; STEINBERG, 2001).

A representação da masculinidade é apresentada por meio dos esportes, da competição, do raciocínio lógico e da marcação heterossexual. Outras representações como sensibilidade, qualidades artísticas, homossexualidade e bissexualidade são desconsideradas. Nas identidades masculinas são "[...] alvo de exclusão, violência e ridicularização" (CECHIN; SILVA, 2012, p. 135-136).

Ken poderia se encaixar na representação inferior de masculinidade apresentada por Cechin e Silva (2012). O boneco representa características que não são compreendidas como masculinas pelos meninos, mesmo apresentando-se como namorado da boneca Barbie nas mídias que exibem esse brinquedo. Por esse motivo, o boneco pode ser excluído da lista de brinquedos preferidos dos meninos, justamente por representar o oposto: agressividade, força física e atitudes rudes (CALDASCOULTHARD; LEEUWEN, 2004).

Ao interferir na construção da identidade da criança, o brinquedo carrega consigo representações de ser macho, que são consideradas hegemônicas (CECHIN; SILVA, 2012). Ken representa tudo o que um menino heterossexual não poderia ser - sensível, delicado, preocupado com a aparência, empenhado em realizar todos os desejos e vontades da namorada.

$\mathrm{Na}$ produção industrial dos bonecos e bonecas, algumas características se sobrepõem a outras, produzindo ideias do que seja o normal e o patológico. Todos aqueles que não apresentam essas características são considerados diferentes e, por isso, têm sua oferta bastante reduzida, são difíceis de serem encontrados e são "menos normais" (CECHIN; SILVA, 2012, p. 137).

A heteronormatividade é um modo de endereçamento, que trata como estranho aqueles sujeitos que não se "encaixam" no padrão normativo. Nesse contexto, destacamos que nossa construção metodológica possui base nos modos de endereçamento fundamentados por Elizabeth Ellsworth (2001). Embasada pelos estudos do cinema, a autora relaciona essa metodologia com a educação. Os modos de endereçamento consistem na relação entre direção e produção de um filme com seus/suas telespectadores/as. Os/as produtores/as buscam compreender quem é o/a seu/sua receptor/a, o que eles/elas pretendem endereçar ao seu público. A autora compreende o “[...] 'modo de endereçamento' como um conceito que se refere a algo que está no texto do filme e que, então, age, de alguma forma, sobre seus espectadores imaginados ou reais, ou sobre ambos" (ELLSWORTH, 2001, p. 13). Essas concepções contribuem para que um filme seja bem aceito em um determinado grupo de receptores e não em outros, por exemplo. Isso acontece devido ao endereçamento do filme, que é produzido para atingir um grupo e não outro, causar emoção ou não para esse público. 
Esse endereçamento contribui com a construção de identidades. As pessoas que não estão sob o foco do filme tentam se aproximar para tornar-se pertencente a esse grupo, ou pode, ainda, desviar-se das informações endereçadas. Além disso, o/a diretor/a de um filme elabora uma projeção do que supostamente agradaria seus/suasreceptores/as. Desse modo, tudo é endereçado: falas, cenários, luzes, atores e atrizes e sons (ELLSWORTH, 2001).

Não existe neutralidade na elaboração de um filme, nem no modo como ele será recebido pelo/a telespectador/a, pois algo escapa nesse caminho que parte da produção do filme até o/a receptor/a. O que é endereçado pelo/a diretor/a está sob seu controle, mas aquilo que chega aos sentidos do/a receptor/a foge de seu controle. Esse espaço entre o endereçamento e a resposta das pessoas não está vazio, ele é composto por relações sociais, concepções históricas e pela subjetividade do sujeito (ELLSWORTH, 2001).

Transpondo essa concepção para a educação, esse espaço pode ser utilizado pelo/a professor/a como uma forma de buscar aproximações com o/a aluno/a, tendo em vista que o que o/a professor/a que endereça não é recebido pelo/a aluno/a com neutralidade. Há opiniões históricas e sociais que interferem no entendimento dos conteúdos, que não podem ser ignorados pelo/a professor/a, "[...] todos os modos de endereçamento "erram" seus públicos, de uma forma ou de outra" (ELLSWORTH, 2001, p. 44).

[...] o espaço da diferença entre endereçamento e resposta é um espaço que carrega os traços e as imprevisíveis atividades do inconsciente, tornando-o, assim, capaz de escapar à vigilância e ao controle tanto por parte dos professores quanto por parte dos estudantes (ELLSWORTH, 2001, p. 43).

Em nossos estudos questionamos: o que o boneco Ken endereça? Quais são seus estereótipos? Que representação de masculinidade ele abarca? Por ser um acessório da boneca Barbie, Ken, criado em 1961, dois anos após o lançamento da boneca Barbie, apresenta uma trajetória controvérsia, visto que é considerado um boneco que representa a heterossexualidade, mas que apresenta características afeminadas $(\mathrm{CE}-$ CHIN; SILVA, 2012).

Outros personagens produzidos como bonecos, destinados aos meninos, possuem características estereotipadas, como braços fortes, expressão rude e são vendidos em caixas cujos cenários lembra aventura e ação. As bonecas para as meninas possuem um olhar gentil, são delicadas, no caso da Barbie, por exemplo, seus pés são projetados apenas para usar salto alto, e são apresentadas em ambientes calmos, em casa, no salão de beleza etc. (CALDAS-COULTHARD; LEEUWEN, 2004).

Entretanto, o personagem Ken não é representado e nem vendido nas condições ditas masculinas. Como acessório da Barbie, o boneco compartilha dos mesmos ambientes que ela, inclusive a "Casa dos sonhos da Barbie". Por ser "diferente" dos demais bonecos, Ken não agrade os meninos e nas palavras de Caldas-Coulthard e Leeuwen $(2004$, p. 21) "[...] a representação visual dos brinquedos situa meninos e meninas em diferentes esferas e transmite significados relacionados ao gênero". Desse 
modo, o boneco rompe com os estereótipos de gênero masculino por ser, ao mesmo tempo, o parceiro do ideal de feminilidade, mas não cumprir com uma representação agressiva e rude da masculinidade.

Embasamo-nos na compreensão de que os artefatos da cultura contribuem com a construção das identidades dos sujeitos e o personagem Ken representa o modelo ideal de namorado, amigo e príncipe quando atrelado ao endereçamento da boneca Barbie. O personagem consiste em um acessório da boneca e representa tudo o que a menina deseja em um garoto: romantismo, delicadeza, preocupação, etc.

Nunes (2010) destaca que esses artefatos culturais apresentam caminhos para as distinções de gênero, ou seja, sinalizam o que é apropriado para meninos e para meninas. Ken não faz parte da brincadeira de meninos e é visualizado por eles como um personagem "afeminado", ao contrário do que acontecem com o universo das meninas. Ele causa estranhamento aos meninos, pois se difere de todos os brinquedos e personagens ofertados pela mídia para eles, afinal, não é agressivo, não apresenta rigidez e força nas formas em que é comercializado.

As identidades são construídas a partir da ideia de representação e pertencimento. Assim, para se identificar com um grupo, a criança buscará se aproximar das características comuns a este (NUNES, 2010). As meninas, por exemplo, ao se identificarem com a boneca Barbie terão como representação de menina a meiguice, a delicadeza, a magreza, entre outras características.

Desse modo, nossas identificações podem partir de diferentes meios, como a mídia, a publicidade, os brinquedos e os filmes. $\mathrm{E}$ a identidade de gênero também é produzida por meio dessas relações, pois "[...] [g]ênero é uma identidade fabricada, produzida ao longo da vida por diversas pedagogias culturais, pois se aprende a viver como homem e como mulher" (NUNES, 2010, p. 60).

Paralelo aos estudos de Nunes (2010), Guizzo (2013) constatou que a cultura da beleza e do culto ao corpo se fazem presente em sala de aula. Em suas observações a autora verificou diversas marcações de gênero e beleza que fazem parte da rotina de meninos/as, como a negação da utilização de sapatos tipo tênis por parte de algumas meninas para as aulas de Educação Física por entenderem que o sapato às deixaria com baixa estatura.

Comportar-se de acordo com os padrões esperados em determinada cultura ou sociedade, como menino (sendo forte, viril, corajoso, etc.) ou como menina (sendo delicada, comportada, meiga, etc.) não é algo dado pela natureza, mas construído socialmente. Ao longo da vida aprendemos através daquilo que nos é apresentado em diferentes meios e instituições, a ser menino ou menina, homem ou mulher (GUIZZO, 2013, p. 41).

Além das brincadeiras no interior da instituição de ensino, os currículos contribuem com as marcações de gênero. Para Bello (2013), meninos e meninas possuem papeis e espaços diferenciados na escola. Os meninos são considerados inteligentes e espertos, enquanto as meninas são entendidas como esforçadas e organizadas, ou seja, o homem é inteligente por natureza, enquanto a mulher necessita de esforço para pensar e desenvolver algumas tarefas. 


\section{Práticas pedagógicas e representações femininas da mascu- linidade}

Oposta a noção de essência, as movimentações constituidoras e constituintes das identidades localizam o sujeito em lutas e embates por sentidos e significados acerca das identidades e das diferenças que nos produzem como sujeitos culturais. Ao atentarmo-nos para o movimento de Hall (2004, p. 89), "[...] as culturas híbridas constituem um dos diversos tipos de identidade distintivamente novo produzidos na era da modernidade tardia. Há muitos outros exemplos a serem descobertos”.

Como intelectual, o/a docente age e interage com sentidos e significados que estão na relação professor/a-aluno/a. Giroux e McLaren (1995) tratam da formação docente como forma de pensar as atividades que constituem a estereotipia e a prática de formação que rompa com ideais de fixidez. Ao entendermos o/a professor/a como um/a intelectual, não fixamos discursos, mas os interpelamos, problematizamos suas estruturas e práticas e indagamos acerca da organização que oferecem. Desse modo, "[...] pedagogia e cultura podem ser vistas como campos de luta que interagem" (GIROUX; MCLAREN, 1995, p. 127). Nessas disputas, o espaço escolar, a prática pedagógica, os discursos midiáticos e os artefatos culturais que são consumidos pelos/ as alunos/as sugerem questionamentos e nos possibilitam pensar e discutir de que modo tais elementos constituem e são constituídos em e pelos nossos olhares.

Ao invés de destituir o/a aluno/a de seu local e tempo de fala, vislumbrar as pedagogias que são ofertadas por artefatos culturais, discursos midiáticos, práticas pedagógicas, noções éticas e morais, sentidos produzidos em relações podem estabelecer outras oportunidades de acesso para que o ensino seja plural e contribua para a constituição de alunos/as e professores/as. "Nesse contexto, a vida escolar deve ser conceituada não como um sistema unitário, monolítico e inflexível de regras e relações, mas como uma arena fortificada em que sobejam constatações, luta e resistência" (GIROUX; MCLAREN, 1995, p. 140).

Menos interessados em uma forma de aprender o que foi ensinado, mas em reconhecer que "[...] o discurso das culturas vividas, enquanto modalidade de crítica,deveria interrogar as formas pelas quais as pessoas criam histórias, memórias e narrativas que pressupõem um senso de determinação e intervenção" (GIROUX; MCLAREN, 1995, p. 146). Desse modo, docentes e discentes podem visibilizar as disputas entre o estruturado conhecimento científico e a subjetividade da prática experiencial. Ser, para além do que nos é ensinado a ser, é uma atividade que permeia a prática pedagógica dos Estudos Culturais.

Conforme Giroux e Mclaren (1995, p. 146),“[...] uma política cultural requer o desenvolvimento de uma pedagogia atenta às histórias, aos sonhos e às experiências que tais alunos trazem para as escolas". A atividade de produção de conceitos, conteúdos, perspectivas e experiências nos sugere a educação, nesta perspectiva, como potencialidade de dialogar, produzir sentidos e significados que não são moldurados por uma lógica cartesiana. Seduzidos pela proposta de uma dupla ruptura epistemológica, estamos interessados em compreender as profundas alterações em sentidos 
produzidos no senso comum e na ciência (SANTOS, 1989). Pensamos com o senso comum para entendermos a estruturação lógica dos métodos e o comprometimento de um viés teórico-político que constitui nossas imagens do mundo e, estas, nos constituem como sujeitos dessa realidade subjetiva e objetiva, concomitantemente.

Entretanto, "a realidade é multiplicidade" tal como nos ensina Gallo (2004). Desse modo, o conhecimento, as sensações, os afetos e a intuição produzem relações entre os sujeitos e suas experiências com a chamada realidade. Se "[...] não há fragmentação artificial da unidade que precisa ser resgatada, mas é a unidade que é artificial, uma fábula criada por nossas ilusões" (GALLO, 2004, p. 43), nossos sentidos e significados formulam, mesmo que provisoriamente nossas localizações espaço-temporais. Cientes da relação constituinte-constituidora, criamos olhares, perspectivas e aprendemos que educação não é currículo ou prática pedagógica exclusivamente, mas também a organização, a sistematização e as relações que constituíram a "[...] ordem do discurso escolar" (SOMMER, 2007, p. 57).

Avisados/as pela prática escolar que foi instaurada e formada pela educação moderna, de base eurocêntrica, fixada em postulados que definem os conteúdos e os passos pedagógicos que são oportunizados na atuação de professores/as sobre a vida e a experiência de alunos/as, a ação desconstrutiva dos estereótipos aparece na formulação de uma prática pedagógica que interage com os brinquedos como artefatos culturais constituídos e constituintes de significados, lógicas e estruturas que embasam ações, perspectivas e sugerem padrões a serem reproduzidos (SOMMER, 2007; GALLO, 2004; GIROUX; MCLAREN, 1995).

Sibilia (2012) explicita que as subjetividades que convivem nos espaços educacionais não as mesmas que frequentaram a escola em seu princípio. Os sujeitos-alvos do processo de moralização e de educação mudaram. No contexto contemporâneo, nosso desafio está na produção de um diálogo que contribua para as relações culturais, sociais e políticas entre os diferentes sujeitos da educação.

[...] a velha ideia de educar o soberano - como se todos continuássemos a ser, em tese, democraticamente livres, iguais e fraternos - $\mathrm{pa}^{-}$ rece seguir inspirando boa parte dos projetos pedagógicos públicos e privados, ainda que as ações concretas insistam em conspirar de diversos modos contra tais preceitos meio embolorados (SIBILIA, 2012, p. 104).

As oportunidades das leituras, das recepções e dos Estudos Culturais que permeiam o currículo, a prática docente e a atividade escolar, estão em considerar os muros da escola, como delimitações físicas que não impedem as percepções, as constituições e as relações entre as vidas dos/as alunos/as e dos/as professores/as de se relacionarem com os conteúdos, com as atividades e com os desejos que impregnam nossos modos de ver o mundo. Entender as possibilidades do/a professor/a como intelectual é relacionar-se com o desejo de fazer das práticas educacionais relações entre os modos de pensar o mundo.

Neste processo, as masculinidades encontram-se nas relações culturais que alteram e foram transformando também as constituições das identidades culturais no 
contemporâneo. Entender a produtividade das relações culturais na compreensão das dinâmicas culturais nos possibilita uma formação pedagógica que incite a contestação, a problematização e as incertezas que indicam diferentes formas de entender como a cultura perpassa nossas noções de normalidade na composição de masculinidades e feminilidades no contexto da cultura.

\section{Considerações finais}

A mídia contribui com a construção da identidade de meninos e meninas. Os bonecos destinados aos meninos possuem características de líderes, são autoritários, guerreiros e apontam, dessa forma, o estereótipo de masculino encontrado socialmente. Ken não se enquadra nesse padrão, pois ele pode ser reconhecido como um acessório da boneca Barbie, que atende prontamente os desejos dela e não se impõe sobre suas relações com Barbie.

Instrumentalizados/as pela análise e interpretação da linguagem, professores/as podem analisar a localização e a temporalidade que os/as alunos/as rementem em suas representações. Desse modo, a prática pedagógica não inicia ao pedido de silêncio do/a professor/a e não elege o que será o conteúdo, em início, no movimento educacional, mas com base nos conceitos, nas formas de entender de que lugar o sujeito constitui seus sentidos, também é ofertado/a ao/à professor/a a oportunidade de interagir com este/a aluno/a.

Códigos, signos, símbolos, práticas, processos e formas de ser e de agir que são produzidos e produtores das relações que indicam preceitos de gênero e sexualidade. Marcas de gênero e sexualidade relacionam elementos do cinema, da mídia, da escola, da prática social e cultural que produz identificações e projeções que identificam mulheres e homens em uma lógica de sentidos que é engendrada pelas relações culturais, sociais, econômicas, políticas e históricas.

Vislumbrar os artefatos culturais como objetos de disputa nos territórios da educação e da cultura é, também, um modo de não fixar, erigir ou mesmo definir, sob o risco de obsolescência, um método de ensino salvacionista. Menos que criar uma análise crítica baseada na retroalimentação de padrões, o olhar dos Estudos Culturais para os/as alunos/as é uma perspectiva que envolve o/a docente como um sujeito interessado nos modos como os discentes produzem seus sentidos e significados.

\section{Referências}

BELELI, Iara. Gênero. In: MISKOLCI, Richard (Org.). Marcas da diferença no ensino escolar. São Carlos: EdUFSCar, 2010, p. 45-74.

BELLO, Alexandre Toaldo. "As meninas são tuas princesas... Os meninos, teus reizinhos... E eu? Eu não sou nada!”. In: GUIZZO, Bianca Salazar; BECK, Dinah Quesada; FELIPE, Jane (Orgs.). Infâncias, gênero e sexualidade: nas tramas da cultura e da educação. Canoas: Ed. ULBRA, 2013, p. 45-61.

CALDAS-COULTHARD, Carmen Rosa; VAN LEEUWEN, Theo. Discurso crítico e gênero no mundo infantil: brinquedos e a representação de atores sociais. Linguagem em (Dis)curso, v. 4, p. 11-34. 2004. 
CECHIN, Michelle Brugnera Cruz; DA SILVA, Thaise. Meninos, bonecos e masculinidade: construção de gênero e brincadeiras simbólicas. Poíesis Pedagógica, v. 10, n. 1, p. 134-154, 2012.

ELLSWORTH, Elizabeth. Modo de endereçamento: uma coisa de cinema; uma coisa de educação também. In: SILVA, Tomaz Tadeu da (Org.). Nunca fomos humanos. Belo Horizonte: Autêntica, 2001.p.7-76.

FOUCAULT, Michel. A ordem do discurso: aula inaugural no Collège de France, pronunciada em 2 de dezembro de 1970. 19 ed. São Paulo: Loyola, 2009.

FURLANI, Jimena. Representações da mulher e do feminino na mídia impressa brasileira: desconstruindo significados na Educação Sexual. In: PARANÁ. Secretaria de Estado da Educação. Sexualidade - cadernos temáticos da diversidade. Curitiba/PR: SEED, 2009, p.131-158.

GALLO. Silvio. A Orquídea e a Vespa: Transversalidade e Currículo Rizomático, In: GONÇALVES, Elisa Pereira (Org.) Currículo e Contemporaneidade - questões emergentes. Campinas: Alínea, 2004, p.37-49.

GARCIA, Wilton. A forma estranha: ensaios sobre cultura e homoerotismo. São Paulo: Edições Pulsar, 2000. (Coleção outras palavras, outras linguagens).

GIROUX, Henry; MCLAREN, Peter. Formação do professor como uma contra esfera pública: A pedagogia radical como uma forma de política cultural. In: MOREIRA, A. F; SILVA, Tomaz. Currículo, cultura e sociedade. 2 ed. São Paulo: Cortez, 1995, p. 125-153.

GREEN, James Naylor. Além do Carnaval: A homossexualidade masculina no Brasil do século XX. Tradução de Cristina Fino e Cássio Arantes Leite. São Paulo: Editora UNESP, 2000.

GUIZZO, Bianca Salazar. Masculinidades e feminilidades em construção na Educação Infantil. In: GUIZZO, Bianca Salazar; BECK, Dinah Quesada; FELIPE, Jane (Orgs.). Infâncias, gênero e sexualidade: nas tramas da cultura e da educação. Canoas: Ed. ULBRA, 2013, p. 29-43.

GUIZZO, Bianca Salazar; BECK, Dinah Quesada; FELIPE, Jane. Infâncias, gênero e sexualidade: articulações possíveis. In: GUIZZO, Bianca Salazar; BECK, Dinah Quesada; FELIPE, Jane. Infâncias, gênero e sexualidade: nas tramas da cultura e da educação. Canoas: Ed. ULBRA, 2013. p. 17-27.

HALL, Stuart. A identidade cultural na pós-modernidade. 10 ed. Rio de Janeiro: DP\&A Editora, 2004.

LOURO, Guacira Lopes. Um corpo estranho - ensaios sobre sexualidade e teoria queer. 1. Ed. 1. reimp. Belo Horizonte: Autêntica, 2008.

NUNES, Luciana Borre. As imagens que invadem as salas de aula: reflexões sobre Cultura Visual. Aparecida: Idéias \& Letras, 2010.

NUNES, Luciana Borre. Gênero e sexualidade: pedagogias contemporâneas. Pro-Posições. Campinas, v. 19, n. 2, maio/ago. 2008. Disponível em: <http://www.scielo.br/scielo.php?script=sci_arttext\&pid=S010373072008000200003\&lng=en\&nrm=iso >. Acesso em: jan. 2015.

SCOTT, Joan Wallach. Gênero: uma categoria útil de análise histórica. Educação \& Realidade. Porto Alegre, vol. 20, n. 2, p. 71-99, 1995.

SIBILIA, Paula. Redes ou paredes: a escola em tempos de dispersão. Tradução de Vera Ribeiro. Rio de Janeiro: Contraponto, 2012.

SANTOS, Boaventura Sousa. Introdução a uma ciência pós-moderna. Rio de Janeiro: Graal, 1989.

SOMMER, Luís Henrique. A ordem do discurso escolar. Revista Brasileira de Educação. v. 12. n. 34 , p. $57-67,2007$. 
STEINBERG, Shirley. A mimada que te tudo. In: STEINBERG, Shirley (Org.). Cultura infantil: a construção corporativa da infância. Rio de Janeiro: Civilização Brasileira, 2001, p. 321-338.

TREVISAN, João Silvério. Devassos no Paraíso: (a homossexualidade no Brasil, da colônia à atualidade). 3. ed. rev.ampl. Rio de Janeiro: Record, 2000.

WHITAKER, Dulce. Mulher e homem: o mito da desigualdade. São Paulo: Moderna, 1988.

\section{Notas}

${ }^{1}$ www.barbie.com

${ }^{2} \mathrm{O}$ vídeo possui duração de 2:54 minutos.

${ }^{3}$ Disponível em: <https://www.youtube.com/watch?v=wJR6HP3ruH4>. Acesso em: 20 out. 2017.

* Mestre em Educação pela Universidade Estadual de Maringá, Maringá, Paraná, Brasil.

**Doutor e mestre pelo Programa de Pós-Graduação em Educação da Universidade Estadual de Maringá, Maringá, Paraná, Brasil.

*** Docente do Programa de Mestrado e Doutorado em Educação da Universidade Estadual de Maringá e Bolsista pesquisadora sênior da Fundação Araucária, Paraná, Brasil.

\section{Correspondência}

Michely Calciolari de Souza - Universidade Estadual de Maringá. Rua Osvaldo Cruz,Zona 7. CEP: 87020200. Maringá, Paran, Brasil.

E-mail:michely_calciolari@hotmail.com - sami.takara@gmail.com - tkteruya@gmail.com

Recebido em 15 de junho de 2016

Aprovado em 04 de novembro de 2017 
